\title{
A PERSPECTIVA METODOLÓGICA EM VYGOTSKY: O MATERIALISMO DIALÉTICO
}

\author{
JOÃO BATISTA MARTINS 1
}

MARTINS, J.B. A perspectiva metodológica em Vygotsky: o materialismo dialético. Semina: Ci. Soc./Hum., Londrina, v. 15, n. 3, p. 287-295, set. 1994.

RESUMO: Discute-se alguns conceitos desenvolvidos pela Psicologia Sovietica (especificamente por Vygotsky, Leontiev e Luria) resgatando, a partir deles, a perspectiva do materialismo histórico e do materialismo dialético para o estudo do desenvolvimento psicológico da criança.

PALAVRAS-CHAVE: Psicologia do Desenvolvimento, Psicologia Soviética

\section{1 - INTRODUÇÃo}

Fica-nos muito claro, quando adentramos nos textos de Vygotsky, a influência do materialismo dialético na constituição de sua teoria. Há que se considerar, no entanto, o momento histórico em que ela foi concebida Rússia pós-revolução de 1917 - e, conseqüentemente, a necessidade de se construir uma psicologia que contemplasse os princípios do materialismo histórico e do materialismo dialético.

A revolução de outubro de 1917 e a implantação do marxismo-leninismo representaram uma transformação radical na sociedade russa e da futura URSS: tanto para o campo social, econômico, político e ideológico, como para o campo das ciências e das idéias.

Com relação à situação da psicologia russa, destacavam-se, neste periodo, duas abordagens que espelhavam a situação da psicologia em outras partes do mundo. isto ê, a fragmentaçäo do corpo psicológico em distintas escolas. Na Rússia, dois autores sintetizavam os movimentos dissonantes dentro da psicologia: Chelpanov. fundador e dirigente do Instituto de Psicologia de Moscou (de 1912 a 1924), era porta-voz do idealismo na psicologia. Para ele,

"...a psicologia propriamente dita devia estudar as leis da alma, que se servem do funcionamento cerebral, mas não se confunde com ele e tem uma entidade própria. [Para ele] o método fundamental da psicologia devia ser a introspecção experimental." (RIVIERE, 1985, p. 24).

Após a revolução, no ano de 1923, ocorreu o I Con- gresso Pan-Russo de Psiconeurologia, oportunidade que permitiu a emergência das tensões latentes entre os psicólogos idealistas e as diversas correntes materialistas que circunscreviam a psicologia soviética. As críticas mais significativas ao idealismo proposto por Chelpanov foram as realizadas por Kornilov. Ele propunha

"uma nova forma de fazer psicologia a que designou de 'reatologia'. Se tratava de estudar, de forma objetiva, as reaçôes humanas em seu ambiente biosocial. [....] tratava de evitar tanto o reducionismo social do psicológico... como o reducionismo fisico...s, sem retificar uma substância espiritual como objeto da psicologia." (RIVIERE, 1985, p. 25).

Seu trabalho levou-o a ocupar o lugar de Chelpa. nov na direção do Instituto de Psicologia de Moscou on de reuniu jovens cientistas com a perspectiva de formular uma nova teoria psicológica (dentre eles se encontravam Luria e Leontiev): Vygotsky começou a trabalhar neste Instituto em 1924 (RIVIERE, 1985).

O enfrentamento histórico entre a psicologia introspectiva da consciência e os novos enfoques objetivos teve na URSS um significado peculiar ao entrelaçar-se com os acontecimentos revolucionários e com a condição global de mudança cultural que vivia aquela sociedade. 0 que em outros paises era uma problemática mais estimulada pela história da psicologia, e com sua consistência interna, na URSS se converteu numa busca de uma alternativa materialista que fosse, ao mesmo tempo, consistente com a filosofia socialmente dominante - o marxismo.

1 - Departamento de Psicologia Social e institucional/CCB - Universidade Estadual de Londrina, Caixa Postal 6001, Londrina, Paraná, Brasil, CEP 86051-970. 
Tendo em vista as diversas correntes que constituiam o campo da psicologia, avaliou-se que nem a psicologia subjetiva proposta por Chelpanov, nem as tentativas para reduzir o todo da atividade consciente a simples esquemas reflexos, proporcionariam um modelo satisfatório da psicologia humana.

Avaliou-se, também, que estas duas correntes psicológicas haviam desmembrado a psicologia, inviabilizando o estudo do comportamento humano complexo. A tendência objetivante de alguns, no entanto, levou os pesquisadores a ignorarem o problema da consciência a caracteristica fundamental que distinguiria o homem dos outros animais. Por outro lado, as idéias marxistas de outros colocavam tal temática como um verdadeiro problema da psicologia, analisável cientificamente?.

Resgatando as idéias marxistas, as propostas de trabalho de Vygotsky, Luria e Leontiev - tinham a seguinte perspectiva

\begin{abstract}
"Examinando esta situaçăo, Vigotskii mostrou que a divisão de trabaiho entre os psicólogos da ciência natural e os psicólogos fenomenológicos havia produzido um acordo implicito, segundo o qual as funções psicológicas complexas, aquelas mesmas funções que distinguiam os seres humanos dos animais, não podiam ser estuda. das cientificamente. Os naturailstas e os mentalisias haviam anificialmente desmembrado a psicologia. Era sua meta, e nossa tarefa, criar um novo sistema que sinteitizasse esias maneiras confitanies de esiudo." (LURIA, 1988, 2,24$)^{2}$.
\end{abstract}

Tratava-se, portanio, de um rabalho metodologi co, no sentido de construir um novo paradigma psicológico que integrasse algumas das contribuiçóes da psicologia da época le de outras disciplinas como a lingülstica. a antropologia, a neurologia etc. 1 com os grandes princlpios do materialismo dialético.

Segundo LURIA (1988), Vygotsky era o maior teórico do marxismo entre eles, e e resgate da metodologia marxista de anălise que vai orientar todo o seu trabalho na construção de uma nova psicologia. Para ele "o mar" xismo era uma ferramenta para pensamento e năo um conjunto de verdades reveladas." (RIVIERE, 1985,, .16$)$.

influenciado pelo trabalho de Marx e Engels, Vygotsky se propõe a procurar as origens das formas superiores de comportamento consciente nas relações sociais que os individuos mantêm com o mundo exterior.

\section{“O abismo existente entre as explicaçöes cientfficas e naturais dos processos elementares $e$ as descriçóes mentalistas dos processos}

complexos não pode ser transposto até que possamos descobrir o meio pelo qual os processos nalurais, como a maturação fisica, e os mecanismos sensórios se entrelaçam aos processos culluralmente deierminados para produzir as funçóes psicológicas dos adultos. Nós precisamos, por assim dizer, caminhar para fora do organismo objetivando descobrir as fontes das formas especificamente humanas de atividade psicologica." (LURIA, 1988, p. 26).

OLIVEIRA (1993) nos aponta algumas infiluências do marxismo na obra de Vygotsky. Segundo ela, alguns postulados básicos marxístas sảo por ele incorporados. tais como

6r) o nodo de produção da vida material condiconta a vida social politica e espiritual do ho men; b) homem es um ser historico, que se consiroói aưravês de suas relaçöes com o mundo nakurat e social. O processo do trabalho (trans. formaça da naiureza) \& o processo privilegiado fuessas jelacoles homem/mundo; c) a sociedade humana a uma iotalidade em constante uransior. maçâo. E um sistema dinâmico e coniraditorio. que precisa ser compreendido como processo om mudanca, em desenvowimento; d) as arans. brmecoses guahiaivas ocorrem por meio de chameda 'shrose diabrica' onde. a parir de ple menos de uma dereminada silltacäo fonomenos novos energenoco $(0,23)$.

No incio do ser Vygotsky diz que o proposito de seu trabaho \& o de ca racterizar os aspectos tipicamente humanos do comportamento, e hipotetizar sobre as maneiras pelas quais as. tas caracteristicas se desenvolveram ao longo da historia da humanidade (perspectiva hilogenetica) a durante a vida dos individuos (perspectiva ontogenérical.

Nesse sentido consicerando que existe uma astreita relação entre o método com a natureza do objeto a ser investigado e que a psicologia de então năo havia elaborado uma metodologia que corresponde as suas expectativas, Vygotsky postulava a necessidade de criar métodos adequados que contemplassem a concepção de homem implicita em seu trabalho, qual seja, a de que ${ }^{20}$ comporamento humano tem aquela "reação iransformadora sobre a natureza' que Engels atribuiu aos objetos [instrumentos]." (VYGOTSKY, 1991, p. 70).

\section{A QUESTÄO DO MÉTODO}

Um ponto central deste método (VYGOTSKY, 1991)

1. Luria (1988b) caracteriza consciência como a "habilidade em avaliar as informações sensórias; em responder a elas com pensamentos e ações criticas e em reter traços na memória de forma que traços ou ações passadas possam ser usados no futuro" (:196), e que o cérebro é o substrato que possibilita seu desenvolvimento.

2. O termo sintese deve ser aqui considerado numa perspectiva do materialismo dialético, o que implica na superação de uma determinada realidade, possibilitando a emergência de algo novo. Esse novo é possivel pela interação entre os mais diversos conhecimentos que, num processo de transformação, possibilita a criação de novos conhecimentos.

Semina Ci. Soc./Hum., v. 15, n. 3, p. 287-295 
é que os fenômenos psíquicos devem ser resgatados enquanto processos em mudança. Analisando o método dominante na psicologia da época, método experimental cuja estrutura geral era a do E-R, Vygotsky sustenta que, mesmo que ele possa ser adequado para o estudo dos comportamentos elementares, não pode servir de base para o estudo de processos complexos, como as formas de comportamento especificamente humanas.

A idéia chave da proposta de Vygotsky, quanto ao método, reflete o contraste enunciado por ENGELS (18-?) entre a abordagem naturalista e abordagem dialética. A primeira parte do pressuposto de que as condições naturais determinam $\mathrm{o}$ desenvolvimento histórico. A segunda, ao contrário, considerando as influências ambientais, afirma que o homem age sobre a natureza e a transforma, criando novas condições de existência.

Vygotsky descreve três princípios para a implementação dessa nova abordagem metodológica. O primeiro é que ela deve visar os processos, o que implica em considerar as mudanças no processo de desenvolvimento humano, de tal modo que sua gênese e evolução possam ser seguidas em determinadas circunstâncias. Tal análise requer, portanto, o resgate da história das funções superiores do homem. O segundo é que ela seja explicativa e não meramente descritiva, ou seja, que ela explicite as relações internas constitutivas dos fenômenos humanos. Na medida em que a história é mudança, tal concepção possibilita o processo de constituição dos comportamentos, o que dá acesso ao seu conhecimento. O terceiro principio refere-se aos comportamentos automatizados - fossilizados - após um longo processo histórico de desenvolvimento, os quais devem ser analin sados nas suas origens, pois nelas, o passado e o presente se confundem e o presente é visto à luz da história.

Para a análise das funções superiores, Vygotsky estabelece dois processos básicos desta metodologia: a unidade de análise e o princípio explicativo, processos esses que articularão teoria e método.

"Com o termo unidade queremos nos referir a um produto de análise que, ao contrário dos elementos, conserva todas as propriedades básicas do todo, não podendo ser dividido sem que as perca. A chave para a compreensäo das propriedades da água são as suas molêculas $\theta$ seu comportamento e não seus elementos quf micos. A verdadeira unidade para a análise biológica ê a célula viva, que possui as propriedades båsicas do organismo vivo." (VYGOTSKY. 1991 a。 p. 4).

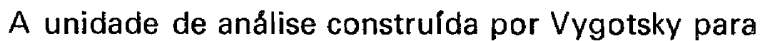
o estudo do desenvolvimento humano - caracterizada pela fala, ação e percepção (VYGOTSKY, 1991) - é uma estrutura psicológica integrada, que permite a integração dos elementos contraditórios. Uma unidade que retém todas as propriedades do todo; a análise, portanto, deve ser holistica, uma vez que os elementos vão adquirindo novos significados quando, no processo histórico, são Semina Ci. Soc./Hum., v. 15, n. 3, p. 287-295 colocados em relação com o todo em que estão integrados.

O princípio explicativo é um conceito que reflete uma certa realidade que, por sua vez, determina fenômenos mentais e torna possivel sua reconstrução.Assim, a unidade de análise circunscreve um campo teórico-metodológico de análise, e o princípio explicativo permite relacionar uma determinada realidade com uma determinada elaboração teórica.

O projeto teórico de Vygotsky implicava a realização de estudos experimentais centrados, principalmente, em duas grandes áreas: 1) a gênese e desenvolvimento das funções superiores na criança, e 2) a influência das variáveis transculturais na natureza dos processos cognitivos (RIVIERE, 1985).

A idéia básica dos estudos sobre desenvolvimento era a de desvelar os processos de construção das funções e, mais especificamente, o papel dos instrumentos e signos em tal construção, assim como a mediação "cultu" ral", representada pelo próprio experimentador. Assim. os experimentos realizados por Vygotsky e seus colaboradores tinham como objetivo explicitar como se desenvolvia a atividade mediada nas crianças - e conseqüentemente o desenvolvimento das funções superiores.

"A idéia de usar dois conjuntos de estímulos um conjunto primário, que tinha de ser dominado, e outro conjunto auxiliar, que podia servir como instrumento para dominar o conjunto primário - tornou-se o instrumento metodológico central em todos os nossos estudos." (LURIA, 1988, p. 28).

Quanto aos estudos transculturais, o princípio que os guiavam era o de que a natureza das funções superiores, na medida em que tem uma origem cultural, são variáveis e dependem das características da cultura em que se configuram.

O momento histórico da URSS era adequado para analisar a influência das variáveis culturais sobre as fun. çōes superiores: percepção, memória, pensamento etc. $O$ programa de mecanização e coletivização do trabalho e da propriedade que se iniciou no final dos anos 20 propiciava uma ampla mudança cultural e na organizaçäo so. cial de milhöes de camponeses e pastores, que se incorporavam as formas coletivas de trabalho e convivência $e$ a uma campanha de alfabetização e de educação. Com is so se estabelecia uma situação que permitia comparar o funcionamento cognitivo de grupos que ainda mantinham as formas tradicionais de organização e cultura com o de outros que estavam passando por um processo de mudança acelerado (RIVIERE, 1985).

Luria realizou uma pesquisa em 1930 na Ásia Central (LURIA, 1990) com o propósito de estabelecer o papel da cultura no desenvolvimento cognitivo. No estudo que realizou, analisou os processos de percepção, generalização e abstração, raciocínio e solução de problemas junto a grupos mais tradicionais e os incorporados na campanha de alfabetização e mudança social. 
Os resultados da pesquisa confirmaram as hipóteses iniciais de trabalho, o que significa dizer que os processos superiores - na medida em que são considerados como atividades instrumentais de adaptação - refletem as propriedades dos mecanismos de interação e das formas sociais de organização em que os individuos estão inseridos.

Segundo LURIA (1988), Vygotsky gostava de chamar este modo de estudo de psicologia "cultural", "histórica" e "instrumental", cada termo reflete uma caracteristica diferente do homem.

“... 'Instrumental', se refere à natureza basicamente mediadora de todas as funções psicológicas complexas [pois] as funções superiores incorporam os estímulos auxiliares, que são tipicamente produzidos pela própria pessoa. (...) 0 aspecto 'cultural' da teoria de Vygotskii envolve os meios socialmente estruturados pelos quais a sociedade organiza os tipos de tarefa que a criança em crescimento enfrenta, e os tipos de instrumentos, tanto mentais como físicos, de que a criança dispóe para dominar aquelas tarefas. (...) O elemento 'histórico' funde-se com o cultural. Os instrumentos que o homem usa para dominar seu ambiente e seu próprio comportamento... foram inventados e aperfeiçoados ao longo da história social do homem." (LURIA, 1988, p. 26).

Tal concepção reflete a posição de Vygotsky de que a consciência e as funções superiores se enraizam no espaço social, na relação com os objetos e pessoas, e nas condições abjetivas de vida social, e que a psicologia deveria, ao elucidar os processos subjacentes ao desenvolvimento humano, levar em conta tais relações.

\section{O CONCEITO DE ATIVIDADE}

O conceito de "atividade" surgiu tanto em Vygotsky como em Leontiev, seu principal elaborador, com a explicação da consciência, na medida em que ela é considerada como emergindo ou constituindo-se no processo da atividade humana.

LEONTIEV (1988) considera que o desenvolvimento da criança é circunscrito pelas relações que ela estabelece com seu meio social, o que a possibilita assimilar "o mundo objetivo como um mundo de objetos humanos reproduzindo ações humanas com eles" (p. 59).

Em outras palavras, a criança apropria-se dos objetos humanos - que são construídos historicamente o que tem como conseqüência a reprodução no individuo de qualidades, capacidades e caracteristicas humanas de comportamento. Sendo assim, podemos depreender que Leontiev considera o desenvolvimento mental da criança como um processo de internalização da experiência do gênero humano.

Durante o processo de desenvolvimento humano observamos mudanças fundamentais nas maneiras como Semina Ci. Soc./Hum., v. 15, n. 3, p. 287-295 o homem se relaciona com seu meio (o que vai "localizá-lo" na sociedade em que vive). Tal processo é determinado pelas condições reais e objetivas de sua vida, 0 que circunscreve as características da psique humana. Assim, cada estágio do desenvolvimento psíquico caracteriza-se por uma relação entre o indivíduo e a sua realidade e por um tipo preciso e dominante de atividade.

"Todavia, a vida, ou a atividade como todo, não é construlda mecanicamente a partir de tipos separados de atividades. Alguns tipos de atividade são os principais em um certo estágio, e são da maior importância para o desenvolvimento subseqüente do individuo, e outros tipos são menos importantes. Alguns representam o papel principal no desenvolvimento, e outros, um papel subsidiário. Devemos, por isso, falar da dependência do desenvolvimento psíquico em relação à atividade principal e não a atividade em geral." (LEONTIEV, 1988, p. 63).

Assim, cada estágio do desenvolvimento é caracterizado por uma "atividade principal", atividade essa que governa as mudanças mais importantes nos processos psíquicos da personalidade dos individuos. Assim, uma mudança na atividade principal proporciona a base para outras mudanças, possibilitando o desenvolvimento da psique da criança. Dessa forma "o critério de transição de um estágio para outro é precisamente a mudança do tipo principal de atividade na relação dominante da criança com a realidade." (LEONTIEV, 1988, p. 64).

Entretanto, para que esse processo venha a ocorrer, de tal modo que o individuo passe de uma atividade para outra (e, conseqüentemente de um estágio para outro), é necessário que haja uma alteração em suas necessidades. Ou seja, para que uma ação surja, é necessário que seu objetivo seja percebido em sua relação com o motivo da atividade (necessidade) em funçăo da qual ela emergiu.

Cabe salientar, no entanto, que é o meio cultural que propicia as condições reais para o desenvolvimento infantil, pois é ele que oferece "problemas" para os individuos, assim como os "instrumentos" e as "ferramentas" para sua solução (RIVIERE, 1985).

Este conceito - o de atividade - está inspirado no conceito de trabalho desenvolvido por Marx e Engels. A atividade humana, mediadora das relaçōes do homem com a natureza, diferencia-se das formas de atividade animal porque ela confere uma nova forma à realidade ou seja, ela é uma atividade criadora. É este caráter que define o significado do trabalho em Marx e Engels, e é através dele que o homem, ao mesmo tempo que age sobre a natureza - modificando-a - modifica sua própria natureza, ou seja, o objeto produzido pelo trabalho é a "objetivação" da própria atividade humana.

O conceito de atividade compõe-se de três elementos: o sujeito ativo (a ação), o objeto (o produto da atividade), o que implica nas habilidades perceptuais do homem para concebê-lo) e o mediador (seja ele uma 
ferramenta, seja ele um significado). O produto da atividade traduz a concretização dos projetos humanos, isto o torna em um "objeto de reconhecimento": o sujeito se reconhece no objeto e é nele reconhecido pelos outros, 0 que faz dele uma produção social/cultural.

VYGOTSKY (1991), no entanto, vai estabelecer uma diferença entre a mediação efetivada pelos "instrumentos" criados pelo homem e a mediação realizada pelos signos. Os instrumentos fabricados - o que possibilita ao hymem concretizar a atividade do trabalho - conduz sua aça em direção ao meio ambiente, de modo que o homem possa transformá-lo. Já as atividades mediadas por signos (a linguagem, por exemplo) são efetivadas em função do próprio sujeito e vão orientar o indivlduo "para si mesmo", conduzindo suas ações psicológicas - na relação consigo mesmo.

"A invenção e o uso de signos como meios auxiliares para solucionar um dado problema psicoIogico (lembrar, comparar coisas, relatar, escother, etc.), é análoga à invenção e uso de instrumentos, sơ que agora no campo psicológico. $O$ signo age como um instrumiento da atividade psicológica de maneira análoga ao papel do instrumento no trabalho." (VYGOTSKY, 1991, p. $59 / 60)$.

Assim, "a mediaçăo tornar possivel atividades psicológicas voluntårias, intencionais, controladas pelo próprio individuo." (OLIVEIRA, 1993, p. 33).

O processo inverso da objetivação do sujeito é o da apropriação e internalização das produções culturais. VYGOTSKY (1991), ao considerar o desenvolvimento histórico dos indivíduos, assinala que as funções humanas (pensamento, linguagem, habilidades, etc.), aparecem duas vezes na vida das pessoas: primeiro a n?vel social, e mais tarde a nivel individual; primeiro entre pessoas e depois no interior da própria pessoa.

A internalizaçäo se caracteriza pela reconstrução interna de uma atividade externa , pois implica numa reorganização das atividades psicológicas sobre a base das operações 3 com signos, o que pressupõe a incorporação da cultura pelo sujeito $e_{*}$ ao mesmo tempo, a configuração do pro̊prio sujeito a a reestruturação das atividades reflexas do organismo.

VYGOTSKY (1991) aponta que, num primeiro momento, o individuo se relaciona com o seu meio através de reações reflexas - conexōes do tipo $S \rightarrow R$. A superação deste estágio se dá quando a criança começa a internalizar os signos e os significados que medeiam as relaçōes humanas, reestruturando suas atividades anteriores, as quais passam a ser mediadas $-S \rightarrow x \rightarrow R$. Assim, o comportamento da criança deixa de ser controlado pelos es- timulos externos aos individuos, passando a ser controlado pelos mediadores por ele internalizados.

OLIVEIRA (1992) chama a atenção para o fato de não se confundir as propostas de Vygotsky com o "determinismo sociológico", tendo em vista que ele resgata a capacidade do individuo em reelaborar os significados, os instrumentos, etc. que o mundo cultural the propõe, reelaboração que se dá através do processo de internalizaçäo.

Um fenômeno paradigmático descrito por Vygotsky para entender o mecanismo de internalização é o processo de aquisição da linguagem. A linguagem na criança aparece inicialmente em sua forma comunicativa - seu comportamento es controlado por significados externos a ela. Em seguida, quando a criança adquire a fala, passa a desenvolver uma fala denominada egocêntrica - ou seja, a criança fala consigo mesma nas atividades que desenvolve. $O$ passo seguinte desse processo é o aparecimento da fala interiorizada, é o que denominamos de pensamento verbal - é o "falar em silêncio" consigo próprio -, ou seja a criança internaliza os significados culturais e os operacionaliza na relação que mantém consigo mesma (ação reflexiva). Tanto a fala egocêntrica como a fala interiorizada têm a função de planejar, coordenar, controlar o comportamento do indivíduo, através dos significados que yai aprendendo - e internalizando - no contato com seu contexto cultural.

\section{A UNIDADE DE ANÁLISE: UMA PERSPECTIYA PARA O ESTUDO DO DESENVOLVIMENTO INFANTL}

Como apontamos anteriormente Vygotsky e seus colaboradores elaboraram alguns experimentos que tinham como objetivo verificar como as pessoas resolviam problemas utilizando instrumentos e signos - atividade mediada. $O$ estabelecimento da unidade de análise - fala, ação e percepção - pode ser vislumbrado a partir de um experimento sobre o papel organizador da fala desenvol. yido por um dos colaboradores de Vygotsky.

"Pediu-se a uma menina de quatro anos e meio
que pegasse o doce [que estava em cima de um
armáriol usando como possiveis instrumentos
um banco e uma vara. A descrição de Levina é a
seguinte: (parada ao lado de um banco, olhando
e, com a vara, tentando sentir algo sobre o armá-
no). 'Subir no banco." (...) "Aquilo ê mesmo um
doce?" (Hesita) 'Eu posso pegắlo com aquele
outro banco." (Pega o outro banco) "Não, não då.
Eu poderia usar a vara." (Pega a vara e esbarra
no doce) "Ele vai se mexer agora' (....)" (VY-
GOTSKY, 1991, p. 28).

A partir deste tipo de experimento Vygotsky pode averiguar que a fala da criança é tão importante quanto a

3. O conceito de operaçäo desenvolvido por Leontiev (1988) descreve os aspectos práticos da realização das açöes, as condiçöes em que sảo efetivadas e aos procedimentos necessários para realizá-la.

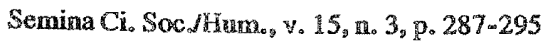


ação para atingir um objetivo, de modo que a fala e ação fazem parte de uma mesma função psicológica complexa. Em um momento qualquer, no decorrer da solução desses problemas, a fala deixa de apenas acompanhar a ação e começa a organizar o comportamento.

"Essas observações me levam a concluir que as crianças resolvem suas tarefas práticas com a ajuda da fala, assim como dos olhos e das máos. Essa unidade de percepção, fala, ação, que, em última instância, provoca a internalização do campo visual, constitui o objeto central de qualquer análise da origem das formas caracteristicamente humanas de comportamento." (VYGOTSKY, 1991, p. 28).

Quando as crianças se confrontam com os problemas em seu cotidiano apresentam uma variedade de respostas, dentre as quais podemos assinalar: tentativas diretas de atingir um objetivo; uso de instrumentos; fala que acompanha a ação, fala dirigida a um adulto, etc. Tais possibilidades estão implicitas nas atividades da criança, atividades que se modificam no decorrer do seu processo de desenvolvimento.

VYGOTSKY (1991) considera que nos primeiros dias do desenvolvimento da criança, suas atividades adquirem um significado próprio num sistema de comportamento social e, sendo dirigidas a objetivos definidos, são refratadas através do prisma do ambiente da criança. O caminho do objeto até as crianças e desta até o objeto passa através de outra pessoa.

Esta estrutura complexa (fala, açăo e percepção), portanto, é o produto de um processo de desenvolvimento enraizado nas ligaçōes entre a história individual $e$ a história social (VYGOTSKY, 1991).

A partir de tais considerações, e dos conceiros an teriormente delineados, podemos caracterizar algumas atividades da criança que circunscrevem os estağgios do desenvolvimento infantil. assim como o desenvolvimentc das funços superiores especificamente humaras.

Num primeiro momento da vida dos indiuducs sus relaçăo com o meio axtemo é mediada pela sue percep-

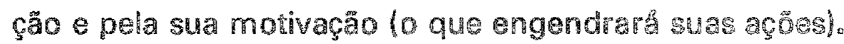
Para VYGOTSKY (1991), säo estes elementos que estara circunscrevendo as atividades (e consequenemente a consciêncial da criança nesse perbodo.

VYGOTSKY (1991a), resgatando as teonias que versavam sobre a relação entre pensamento e linguagem Stern, Piaget, Watson, Kochler, Yerkes, Buehler, etca - a partir de seus experimentos comparativos entre chim. panzés e crianças, estabeleceu que o pensamento a fala têm raizes genéticas diferentes, e que essas duas funçőes se desenyolvem a longo de trajetórias diferentes e inde. pendentes. Assim, podemos dizer que este periodo se caracteriza como uma fase pré-verbal no desenvolvi. mento do pensamento e uma tase preintelechal no desenvolvimento da linguagem.

4. Quadro elaborado por Oliveira, 1993, pag. 47

Scmina Ci. Soc / Humo, v. 1S, n. 3, p. 287-295
"O balbucio e o choro da criança, mesmo suas primeiras palavras, são claramente estágios do desenvolvimento da fala que não tem nenhuma relação com a evolução do pensamento. Essas manifestações geralmente têm sido consideradas uma forma de comportamento predominantemente emocional." (VYGOTSKY, 1991a, p. 37).

Entretanto, a função social da fala já é aparente durante o primeiro ano de vida da criança - na sua fase pré-intelectual do desenvolvimento da fala - o que permite à ela, por um lado, uma ação no ambiente sem a mediação da linguagem e, por outro lado, apesar dela não dominar a linguagem enquanto um sistema simbóli$\mathrm{Co}$, que ela se manifeste verbalmente através do choro, do balbucio, do riso, etc., assegurando uma certa comunicação com os que a rodeiam.

Para Vygotsky,

"...o momento de maior significado no curso do desenvolvimento intelectual, que dá origem às formas puramente humanas de inteligência prática e abstrata, acontece quando a fala e a atividade prática, então duas linhas de desenvolvimento, convergem." (VYGOTSKY, 1991, p. 27).

Assim, o percurso do pensamento fque tem suas origens na ação prática) ao encontrar-se com o da linguagem (que tem origem nas relações sociais), vai propiciar a emergência de uma nova forma de funcionamento psicológico: a fala torna-se intelectual e o pensamento verbal, mediado por significados dados pela linguagem.

"Esse instante crucials em que a fala começa a servir ao intelecto e os pensamentos comecam a ser verbalizados, 8 indicado por dols sintomes objeivos inconfundiveis: 11 a curiosidace adva 6 repentina de crianca peles palaves. stuks pop guntas sobre cade colsa nova (oo); e 2 ) a consen. quente ampliaçäo de seu vocabutario, que ocone de foma rabide a as salos." WVGOTskY. $19912,0.37$.

Assimtemos

FASE PRE -LNGUISTICA DO PENSAMENTO

- utilizaça de instrumenos

- ineligencia prâtica

PENSAMENTO VERBAL E LINGUAGEM RACIONAL

- transformação do biologico no sỏcio-histónico

FASE PRE INTELECTUAL DA LINGUAGEM

- alvio amocional

- funçอ socia ${ }^{4}$ 
A linguagem é mediadora para o salto qualitativo ${ }^{5}$ que ocorre entre o reflexo sensorial e o mundo racional, pois ela vai possibilitar ao individuo elevar-se para um novo nivel no curso de seus psíquicos; o que vai caracterizá-lo como um "fator de estruturação de toda a vida consciente do homem em seu conjunto" (LURIA, 1985, po $113 / 114$ )

A linguagem promove alterações significativas na vida da criança, pois ela permite lao designar objetos e acontecimentos com palavras soltas ou combinações entre elas), destacar ditos objetos, fixar a atenção neles e retê-los na memória. Em virtude disso, a criança se torna capaz de relacionar-se com os objetos do mundo exterior atê na ausência destes, inserindo-se no universo das re. presentações mentais.

“.. a linguagem dobra o mundo perceptivel, permite guardar a informação obtida do mundo exterior e criar um mundo de imagens internas. É făcil assinalar a transcendência que tem o surgimento deste mundo "interior" de imagens lpossfvel através do mecanismo de internalização] que aparece sobre a base da linguagem e que o homem pode utilizar em sua atividade." (LURIA, 1985, p. 111/112).

Alếm disso, a linguagem abstrai os atributos essenciais das coisas e as configuram em determinadas categorias (formação de conceitos). Esta possibilidade de assegurar o processo de abstração e generalização constitui outra caracteristica transcendental da linguagem para a formação da consciência.

A linguagem também possibilita ao homem reestruturar essencialmente os seus processos de percepçẫo do mundo exterior; ela muda substancialmente os processos de memória, convertendo-a em uma atividade mnemônica consciente; permite ao homem desligar-se da experiência imediata e assegura o nascimento da imaginação, servindo de base para a criatividade, orientada e governåvel。

Enfim, com aparecimento da linguagem a criança começará a desenvolver um novo tipo de atividade - circunscrita agora pela unidade da fala/ação/percepção. LEONTIEV (1988) e VYGOTSKY (1991) vão caracterizar, a partir desse momento, um novo estágio do desenvolvimento da criança, cuja atividade principal é a brincadeira (o jogo simbólico). A operação que caracteriza tal ativida. de é a de substituir um objeto pelo outro (o que também acontece com os gestos, com o desenho e nas primeiras tentativas de escrita da criança), ou seja, a criança exercita o universo simbólico que se cria $_{\text {\& }}$ e internaliza a partir de suas relações.

Vygotsky vai considerar como brinquedo especificamente as atividades que se desenvolvem a partir da imaginação infantil, como, por exemplo, as brincadeiras de "faz de conta". Ele descreve dois momentos distintos no processo de desenvolvimento do brinquedo. Num primeiro momento, o significado do brinquedo é determinado pela ação e pelos objetos (percepção), ou seja. pelas condições concretas em que as crianças se encontram. Na medida em que as crianças adquirem a lingua. gem, elas adquirem a capacidade de libertarem o seu funcionamento psicológico dos elementos concretos que a rodeiam. Na brincadeira, portanto ${ }_{*}$ a criança age numa situação imaginária, situação essa determinada pelo significado estabélecido pela brincadeira, e não pelos elementos reais utilizados no jogo.

"No brinquedo, a criança opera com significados desligados dos objetos e ações aos quais estão habitualmente vinculados. [...] No brinquedo, espontaneamente, a criança usa sua capacidade de separar significado do objeto sem saber o que está fazendo da mesma forma que ela não sabe estar falando em prosa e, no entanto, fala, sem prestar atenção às palavras. Dessa forma. através do brinquedo, a crianca atinge uma definição funcional de conceitos ou de objetos, e as palayras passam a se tornar parte de algo concreto." (VYGOTS. KY, 1991, p. 112/113).

Tais situaçőes imaginárias vão proporcionar à criança reconstruir as suas condições reais de vida ao ni. vel da imaginação, pois, no brinquedo, ela sempre se comporta além do comportamento habitual de sua idade. além de seu comportamento diårio. $O$ brinquedo conte̊m. portantos todas as tendências do desenvolvimento sob forma condensada vindo a criar "zonas de desenvolvimento proximal" ${ }^{(6)}$ Nesse sentido, o brinquedo pode ser considerado como uma atividade condutora que deter mina o desenvolvimento da criança.

5. Este termo descreve as mudanças que ocorrem durante o processo de desenvolvimento das atividades humanas. Entende-se que as funções superiores (memória, atenção voluntária, percepção, etc.) não se desenvolvem paralelamente, mas durante o processo e a partir das relaçōes que o homem estabelece com seu meio. Nesse sentido, WERSTCH (1985) esclarece: "Vygotsky sustenta que, em determinados momentos do aparecimento de um processo psicológico, novas forças do desenvolvimento e novos principios explicativos entram em jogo. Nesses momentos se produz, segundo Vygotsky, um 'salto' na natureza do desenvolvimento... e, por isso, os principios que anteriormente eram capazes de explicar o desenvolvimento, já não podem fazê-lo... um novo conjunto de princípios, resultado de sua reorganizaçäo deve ser incorporado na estrutura explicativa geral." (p. 37/38).

6. Este conceito foi elaborado por Vygotsky (1991) com a perspectiva de confirmar a hipótese de que a aprendizagem é imprescindivel para o desenvolvimento humano. A zona de desenvolvimento proximal descreve a distância entre o nivel de desenvolvimento real aquilo que a criança consegue realizar sozinha, independente do outro - e o nlvel de desenvolvimento potencial - aquilo que a criança consegue resolver com a ajuda de um adulto ou de alguém mais velho. Na medida em que a criança aprende alguma coisa, ela transforma aquilo que era potencial, em real, criando nova zona de desenvolvimento proximal, ampliando suas potencialidades, conseqüentemente.

Semina Ci. Soc./Hum., v. 15, n. 3, p. 287-295 
O brinquedo, assim como as atividades deste estágio que se caracterizam pela operaçäo de substituir um objeto por outro - ou seja, que operam no nivel da representação, no nivel simbólico - vão possibilitar a emergência da linguagem escrita na vida da criança, quando ela entrar na escola; caracterizando um novo estágio do desenvolvimento infantil, cujas atividades estão relacionadas com o meio escolar. A entrada na escola, por outro lado, vai estabelecer um novo "status" para a criança na relação que estabelece com seu meio, o que implica na emergência de novas necessidades e motivações para a criança.

LEONTIEV (1988) nos aponta algumas mudanças na vida da criança com relação à sua entrada na escola:

\begin{abstract}
"É diffcil exagerar a significação deste fato na vida infantil. Todo o sistema de suas relações ê reorganizado. [...] 0 ponto essencial é que agora não existem apenas deveres para com os pais e professores, mas que há, objetivamente, obrigaçöes para com a sociedade. Estes são deveres de cujo cumprimento depende sua situação na vida, suas funções e paperis sociais e, por isso, 0 conteúdo de toda a sua vida futura." (p. 61).
\end{abstract}

Ao descrever a história do desenvolvimento da escrita, LURIA (1988a) aponta várias transformações desta atividade: temos inicialmente a escrita indiferenciada; a escrita pictográfica; a escrita ideográfica; e finalmente a escrita alfabética. No entanto, para que esse processo se efetive, é necessário que a criança descubra que "se pode desenhar, além de coisas, também a fala".

A linguagem escrita caracteriza-se como uma atividade mediada e por um tipo especifico de operação: ela é uma representação de uma representação o que implica num nivel mais abstrato na concepção da realidade por parte da criança. Ou seja,

"Um sistema de signos que designam os sons e as palavras da linguagem falada, os quais, por sua vez, são signos das relações e entidades reais. Gradualmente, esse elo intermediário (a linguagem falada) desaparece e a linguagem escrita converte-se num sistema de signos que simboliza diretamente as entidades reais e as relações entre elas." (VYGOTSKY, 1991, p. 120).

Além disso, podemos dizer que ela é a expressão de uma sintese entre os elementos que compõem a unidade de análise proposta por Vygotsky, qual seja, fala/açäo/percepção. Assim temos os seguintes elementos desta atividade: a ação - que é o próprio ato de escrever; o objeto - a escrita em si, expressando significados, os quais estão relacionados com o conteủdo da mensagem a ser emitida; e o mediador - lápis, caneta, instrumentos utilizados para a efetivação da ação, assim como as representações mentais que mediarão tal ação.

A partir das noções acima explicitadas, vemos o Semina Ci. Soc./Hum., v. 15, n. 3, p. 287-295 quão dinâmica é a proposta de Vygotsky e de seus colaboradores para o estudo do desenvolvimento. Desenvolvimento que é abordado não como uma seqüência orde-

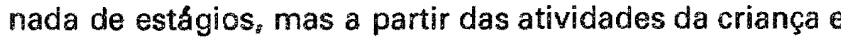
dos saltos qualitativos que se efetivam no seu processo histórico.

\section{ALGUMAS CONSIDERAÇÖES TEÓRICO-PRÁTICAS}

São várias as implicações da teoria soviética para a análise do desenvolvimento humano, principalmente no que se refere à prática pedagógica (RIVIERE, 1985, OLIVEIRA, 1993). No entanto, gostaria aqui de resgatar a sua especificidade, tendo em vista, a tentativa de alguns aucores em a justaporem com a teoria piagetiana.

Sem dưvida ${ }_{s}$ as teorias destes autores (Piaget e Vygotsky) têm muito em comum: são construtivistas, interacionistas, concebem o ser humano como agentes ativos em seu processo de desenvolvimento, etc. (LEITE, 1991). Tais perspectivas podem ser percebidas mais claramente quando relacionadas com algumas atividades escolares (ROCCO, 1990).

No entanto ${ }_{s}$ as diferenças entre estes autores devem ser asseguradas, pois são diferentes as correntes filosóficas que utilizam para elaborarem suas teorias, o que vai împlicar em posiçōes politicas educacionais diferenciadas, quando implementadas na prática pedagógica (SOUZA \& KRAMER, 1991). Em termos de abordagem do desenvolvimento, por sua vez, este fato vai engendrar análises diferentes do processo, como por exemplo, a questăo da relaçăo aprendizagem $x$ desenvolvimento, a análise da "fala egocêntrica", a questäo da avaliação escolar, etc.

OLIVEIRA (1993) assinala que não se trata de descartar uma teoria em favor de outra, nem de agrupá-las, mas sim de aprofundarmos as possibilidades de cada teoria "para que haja um real aprimoramento da reflexăo sobre o objeto que está sendo estudado" (OLIVEIRA, 1993, p. 104).

Nesse sentido, e na medida em que a psicologia de Vygotsky aponta para novas perspectivas para o entendimento do humano, suas idéias vêm contribuir para a construçäo de um novo paradigma para a psicologia (conforme propõe BOOK, 1993).

Com a queda do muro de Berlim, com a dissolução da URSS, a expansâo do neoliberalismo e o "fim da história", surge a necessidade de se resgatar - no estudo dos fenômenos humanos - as influências do meio sóciocultural, em suas mais variadas dimensōes (politica, eco-

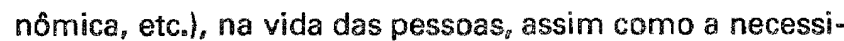
dade do resgate do homem enquanto um ser histórico produto e produtor da sociedade em que vive, implementando-se a emergência de um paradigma que ${ }_{v}$ a partir dos principios da dialêtica, explicite as relaçöes internas constitutivas dos fenómenos humanos.

Considerando que estamos inseridos num meio em que as relaçōes sociais são circunscritas, principalmente, por uma ordem econômica - a capitalista (que vai mediar 
a relaçäo do homem com seu trabalho) - o projeto de mudança que se instaura para a psicologia (a partir da psicologia soviética) deve ser circunscrito pelo desenvolvimento de uma concepção de homem, de cultura e de sociedade, e vinculado a um projeto politico de sociedade.

"Esse conhecimento deve emergir do trabalho de desvelamento do objeto e não da comparação das formas como se constitui com a forma ideal que possamos ter em mente [como acontece, por exemplo com a psicanálise, e com a teoria piagetiana)." (BOOK, 1993).

É sob estas perspectivas que a psicologia poderå promover - atravês da pesquisa, da produção de conhecimentos, da reflexão - uma efetiva mudança em suas possibilidades históricas e nas relações que estabelece com o meio social. É através do resgate de sua historicidade - enquanto uma ciência - e da afirmação da historicidade humana, que se encontram as possibilidades de uma nova psicologia, propiciando uma compreensão mais dinâmica das mudanças sociais que vêm ocorrendo neste final de século.

MARTINS, J.B. The methodological perspective in Vygotsky: the dialetical matherialism. Semina: Ci. Soc./Hum., Londrina, v. 15, n. 3, p. 287-295, Sept. 1994.

ABSTRACT: Some concepts developed by the Soviet Psychology (specially by Vygotsky, Leontiev and Luria) are discussed. Based on the concepts, the historical and dialetic materialism for the children psychological development study are revived.

KEY-WORDS: Development Psychology, Soviet Psychology

\section{REFERÊNCIAS BIBLIOGRÁFICAS}

BOOK, A.M.B. O desafio da construção de uma nova psicologia. São Paulo: [snl, 1993. (Mimeo).

ENGELS, F. Dialética da Natureza. Rio de Janeiro: Leitura [18--?].

LEITE, L.B. As dimensöes interacionista e construtivista em Vygotsky e Piaget. Cademos CEDES, Campinas, y. 24, p. 25-31, 1991 .

LEONTIEV, A.N. Uma contribuição ả teoria do desenvolvimento da psique infantil. In: VIGOTSKII, L.S. et al. Linguagem, Desenvolvimento e Aprendizagem. 2.ed. São Paulo: f́cone, 1988. p. 59-83.

LURIA, A.R. Desenvolvimento Cognitivo: seus fundamentos culturais e sociais. São Paulo: Ícone, 1990.

Vigotskii. In: VIGOTSKII, L.S. et aL Linguagem, Desenvolvimento e Aprendizagem. 2. ed. São Paulo: ficone, 1988. p. 21-37.

desenvolvimento da escrita na criança. In: VIGOTSKII, L.S. et al Linguagem, Desenvolvimento e Aprendizagem. 2 ed. São Paulo: lcone, 1988a. p. 143-189.

cérebro humano e a atividade consciente. In: VIGOTSKII, L.S. et al. Linguagem, Desenvolvimento e Aprendizagem. 2 ed. São Paulo: lcone, 1988b. p. 191-224.
-. Introduccion evolucionista a la psicologia. Barcelona: Martinez Roca, 1985; po 99 118.

OLIVEIRA, M.K. de. Vygotsky: alguns equivocos na intepretação de seu pensamento. Cadernos de Pesquisa, v. 76, p. 67-69, maio 1992.

desenvolvimento um processo sócio-histórico. São Paulo: Scipione, 1993.

RIVIERE, A. La Psicologia de Vygotski. 2. ed. Madrid: Visor, 1985.

ROCCO, M.T.F. Acesso ao mundo da escrita: os caminhos paralelos de Luria e Ferreiro. Cadernos de Pesquisa, $v_{m} 75_{*} p_{z}$ $25-33$, nov. 1990.

SOUZA, S.J. KRAMER, S. O debate Piaget/Vygotskye as polfticas educacionais. Cadernos de Pesquisa, v. 77, p. 69-80, maio 1991.

VYGOTSKY,L.S. A Fomação Social da Mente. 4. ed. São Paulo: Martins Fontes, 1991.

$$
\text { Pensamento e Linguagem. 3. ed. São Paulo: }
$$

Martins Fontes, 1991a

W ERTSCH, J.V. Vygotsky y la Formación Social de la Mente. Buenos Aires: Paidós, 1985.

Recebido para publicação em 29/10/1993 